\title{
KenSea - development of an environmental sensitivity atlas for coastal areas of Kenya
}

\author{
John Tychsen, Ole Geertz-Hansen and Jesper Kofoed
}

The Kenya coastline extends $600 \mathrm{~km}$ from the border of Tanzania in the south to the border of Somalia in the north (Fig. 1). The Kenyan coast features a diverse marine environment, including estuaries, mangroves, sea grass beds and intertidal reef platforms and coral reefs, which are vital for the reproduction of marine organisms. These coastal ecosystems are regarded as some of the most valuable in Kenya but face serious threats from the ever increasing human pressure of tourism, industrial pollution, destructive fishing, mangrove logging and other unsustainable uses of marine resources.

Another serious threat is the maritime transportation activities along the coast and at the ports. It is estimated that at any given time more than 50 ships operate in the major shipping lanes off the Kenyan coast, of which about nine are oil tankers with capacities ranging from 50000 to 250000 tonnes. Furthermore, the harbour of Mombasa serves as the major port for countries in East Africa.

In recognition of the risks posed by oil pollution the government of Kenya and the commercial petroleum industry agreed to develop a National Oil Spill Response Contingency Plan (NOSRCP) with the purpose of enabling a speedy and effective response to any oil spill within the territorial waters of Kenya. An important element of this plan was the mapping of the coastal resources and the development of an environmental sensitivity atlas showing the vulnerability of the coast to marine oil spills.

In 2004, the Government of Kenya approached the United Nations Development Program (UNDP) in Kenya for financial support to develop an environmental sensitivity atlas. The project was approved and forwarded for funding by the Danish Consultancy Trust Fund administrated by United Nations Operational Program (UNOPS) in Copenhagen. The project was announced in Denmark, and the KenSea group headed by the Geological Survey of Denmark and Greenland (GEUS) was awarded the contract.

The project comprises four phases: (1) data compilation and development of the KenSea database, (2) development of a coastal classification for Kenya, (3) development of the sensitivity index jointly with a group of stakeholders, and (4) compilation of the KenSea environmental sensitivity atlas (Tychsen 2006).

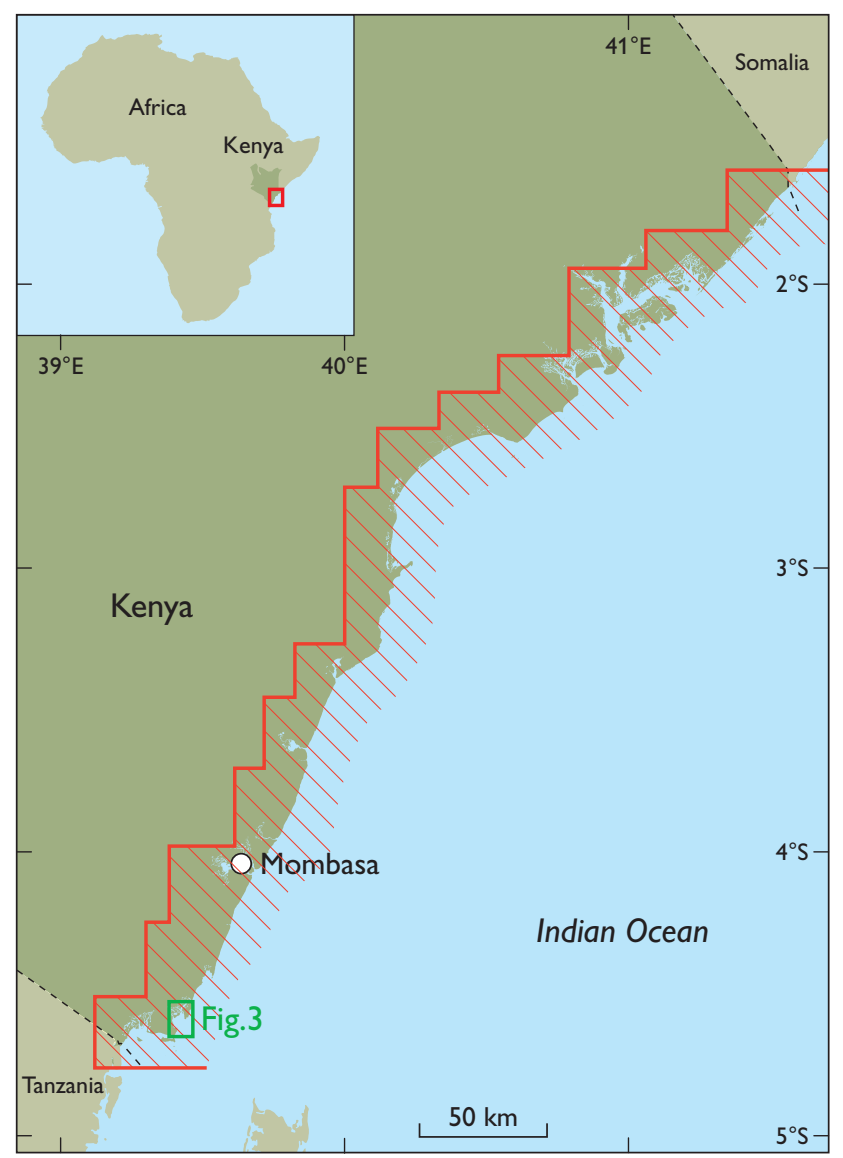

Fig. 1. The coastal area of Kenya (red frame on index map) showing coverage of the KenSea coastal sensitivity map (ruled area). Green frame, location of maps shown in Fig. 3.

\section{Development of the KenSea database}

In the 1990s the Eastern Africa Coastal and Marine Resources Database and Atlas (UNEP 1998) was developed by the United Nations Environmental Programme. This database contains a variety of datasets covering bioscience, geoscience and human use, which have been incorporated either directly or as guidelines for further investigations in the KenSea database (KenSeaBase). However, the UNEP atlas has been produced at the scale of 1:250 000, implying a lower degree of spatial resolution than the scale of 1:50 000 requested for the KenSea project. 


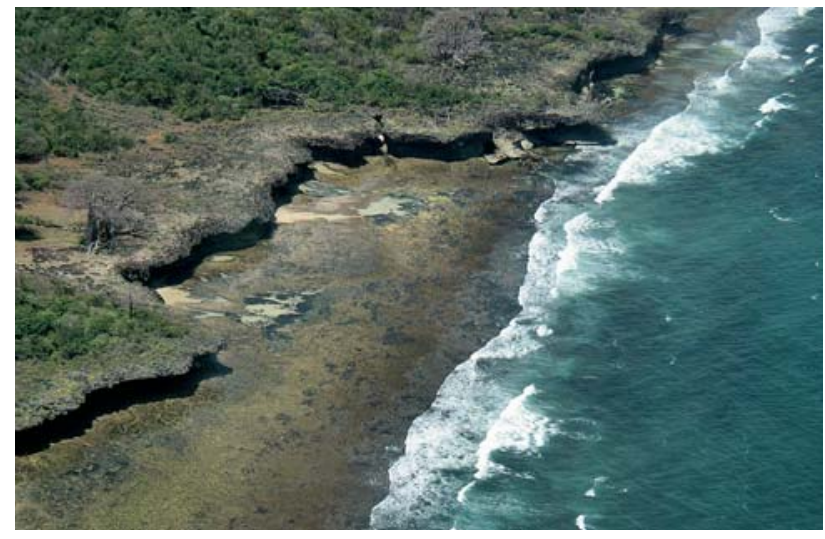

Fig. 2. Pleistocene coral limestone cliffs typical of the Kenyan coast.

Following a kick-off seminar with all stakeholders, the team from the KenSea group visited a large number of government agencies, ministries, private companies and national as well as international non-governmental organisations to collect additional and updated data. All collected data were digitised and included in the KenSeaBase, and preliminary maps were printed. Based on these preliminary maps, a field programme for data verification and additional data collection was developed and carried out. The results were integrated into the KenSeaBase and logistic and topographic maps and coastal resource maps were produced.

\section{Development of a coastal classification for Kenya}

Many attempts have been made worldwide to classify coastlines with respect to their vulnerability to oil pollution. These classifications are usually based on the geomorphology, the degree of exposure to wind and waves, and other relevant conditions. Most of these classifications were inspired by Gundlach \& Hayes (1978) and Baker et al. (1994).

The classification adopted for the KenSea project is a further development of these classifications to meet the conditions in Kenya. In addition to coastal geomorphology and degree of exposure, the ecological value and biodiversity of this particular stretch of coastline is taken into account, as well as the ability of the particular coastal types to facilitate selfcleaning and the conditions for removing a potential oil spill. The resulting classification comprises seven categories, each of which can be described in terms of its geomorphology, ecological value and vulnerability to an oil spill (Tychsen 2006).

\section{Rocky coast}

Much of the Kenyan coast is formed by 4-6 m high Pleistocene coral limestone cliffs (Fig. 2). At present-day sea level they are exposed to wave erosion, resulting in an irregular and rugged appearance. In the upper part of the intertidal zone biological activity is sparse. Subtidal rocks and man-made hard-surface structures such as piers and wharfs may develop a richer flora and fauna, resembling the conditions found on reefs. The exposed cliffs are regarded as less sensitive to oil pollution than most other habitats because of the sparse biological activity, and because the exposure to waves makes the surface to some extent self-cleaning.

\section{Sandy beaches and dunes}

Two types of sandy shores are present along the Kenyan coast: (1) gentle to steep sandy beaches without protection from a reef. The beach is often backed by one or a series of windblown sand dunes. The sand may be of terrestrial origin and supplied by the larger rivers. (2) Gently sloping beaches sheltered behind a reef are common along the coast and the sand is often white calcareous sand of marine origin (coral sand).

Species diversity on sandy beaches is usually low. Above the high-water line, only a few burrowing crabs and amphipods are usually found. The density and diversity of crabs, bivalves, polychaetes and other marine invertebrates increases in the intertidal zone, but remains low compared to most other habitats. Fine-grained sandy beaches are less sensitive to oil pollution due to their relatively sparse biological activity. Furthermore, they are relatively easy to clean since oil does not penetrate deep and can be removed either manually or by use of machinery. On the other hand, coarse sand or gravel is more sensitive as the oil can sink deep into it, and the oil may therefore be impossible to remove.

\section{Coral reefs and reef flats}

Most of the Kenya coastline is fringed by a major barrier reef complex that includes the most diverse ecosystems in the marine environment. The up to $2 \mathrm{~km}$ wide shallow-water reef flats between the coastal cliffs and the reef crest comprise fossil reefs currently eroded by wave action. Active reef growth occurs at the reef crest and on the slope facing the ocean where coral reef growth occurs to depths between 20 and $25 \mathrm{~m}$. The main part of the reefs are subtidal, and are therefore sheltered from direct contact with a possible oil slick. However, reef crests are usually exposed at low tide and the intertidal corals will be killed immediately by contact with oil. The deeper parts of the reef may also be endangered as waves break on the crest and fine oil droplets become dispersed in the water column. Recovery of damaged coral reefs may take several decades, and restoration techniques are usually not very successful. 


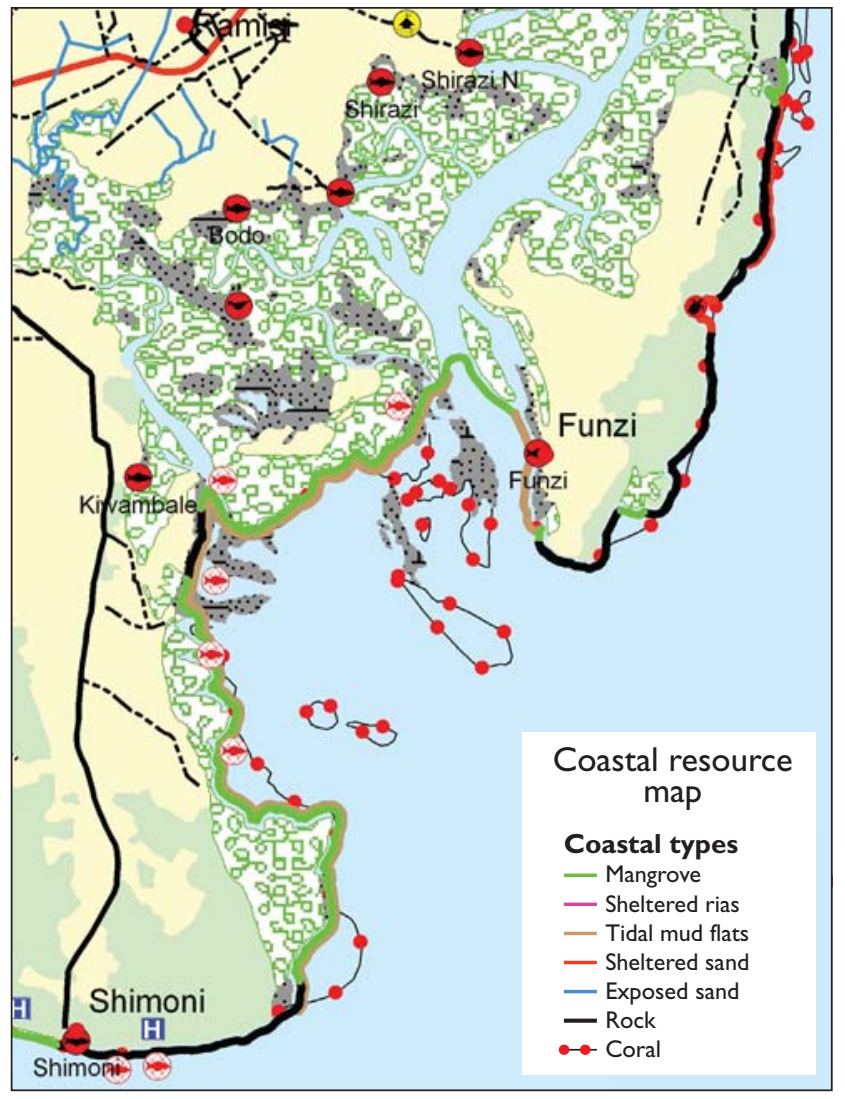

Human use

- Major town

- Town

- Settlement

$\checkmark$ Water intake

(4) Historical/cultural site

it Hotel

- Ferry crossing

Fish traps
Fish landing site
\pm Air strip
— Main road
- Road
-... Track

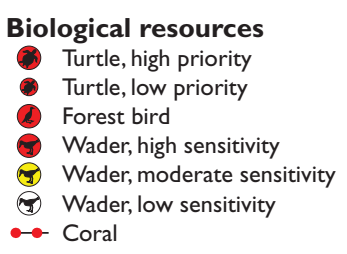

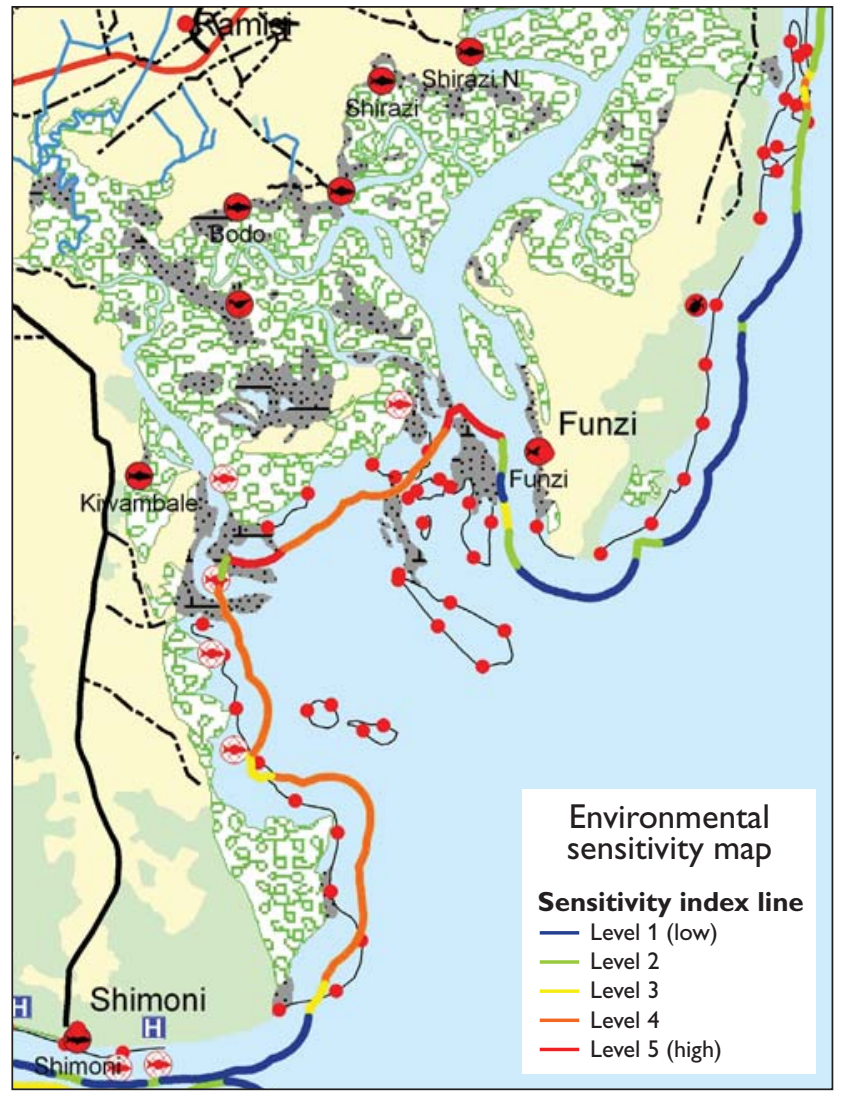

Fig. 3. Examples of a coastal resource map (left) and an environmental sensitivity map (right) from the KenSea environmental sensitivity atlas (see Fig. 1 for location)

\section{Rias}

Rias are drowned river valleys or estuaries. The typical ria has a steep slope or a sheltered cliff, often with a narrow subtidal muddy beach with a few mangrove trees. The sheltered environment of the ria has only little self-cleaning capacity, although it is often possible to clean from the seaward side because of its narrow extent.

\section{River mouths and estuaries}

The rivers in the area form large, gently sloping floodplains with extensive estuarine zones characterised by fluctuating salinity. The mouths of smaller rivers are often hidden behind mangrove creeks.

Few plant species apart from mangroves are adapted to low or fluctuating salinities. The biodiversity is therefore low within the estuaries, although the density is usually very high due to the continuous supply of food and nutrient from the river. The high density of bivalves, snails and other benthic invertebrates usually attracts many birds. Tidal currents can carry any oil pollution far into the estuary and thus into contact with a high density of food items. Therefore the sensitivity is very high. Flushing and self-cleaning is limited to the seasonal high flow situations.

\section{Mangroves}

Mangroves have a high productivity as they profit from nutrients from both land and sea, and mangrove detritus is often the main source of energy fuelling the estuarine food webs. Mangroves are favoured by fine-grained nutrient-rich sediment, and are therefore often associated with estuaries and other freshwater outlets.

While the diversity of mangrove tree species is limited, they create a multitude of niches suitable for a vast diversity of other organisms. Oil can be acutely toxic to the mangrove as clogging of the aerial roots by oil may hinder proper ventilation 
of subsurface parts and lead to suffocation and stress, and eventually death. Clean-up operations may prove extremely difficult due to the low energy environment of mangrove forests.

\section{Intertidal mud flats}

Sheltered mangroves in creeks or bays are often fringed by a broad intertidal mudflat. These are characterised by a high density of marine invertebrates such as mussels, snails and crustaceans. Although diversity is usually low they are important feeding grounds for aquatic birds. The mudflats are sensitive to oil spills since they are difficult to clean mechanically without mixing the oil into the sediment. Where mangrove forests are associated with mudflats the clean-up is even more difficult for both habitats.

\section{Development of a sensitivity index}

The oil spill sensitivity ranking is designed to help decisionmakers to prioritise the available resources and to focus the emergency response on the most vulnerable areas, both (1) during the pre-spill planning, in order to prepare appropriate response strategies and (2) during an oil spill combat in order to plan and continuously optimise the response strategy under the given conditions and limitations (oil type, weather, equipment, crew, etc.).

\section{Planning the clean-up operation and avoiding post-spill damage}

The goal of oil spill response is to minimise the overall impacts on natural and economic resources as well as cultural assets, but some aspects will be of greater concern than others. The sensitivity ranking for a given stretch of coastline therefore includes the actual sensitivity of the present resources or assets, and a more subtle evaluation of importance or value.

The ranking should integrate a multitude of data such as geomorphological and geological properties, wave exposure, biological diversity and productivity, oil behaviour, ease of clean-up, human use and cultural assets. Although these properties are not directly comparable or quantifiable the outcome should ideally be a simple statement, a numerical index value, or a colour code. The comparison and evaluation of incomparable properties is a matter of balancing often conflicting interests, and no perfect system can be devised. A complicated system is not necessarily better or more accurate than a simple system or qualified judgments. Therefore, it is essential that the amount of detail matches the purpose, and leaves the decision-makers with some alternatives.

The total sensitivity index developed for the KenSea atlas embraces three main themes: (1) coastal type, (2) biological resource, and (3) human use. For each theme an index value that incorporates the index values for the various attributes encompassed by the particular theme has been allocated for a particular stretch of coastline.

The index value for the individual attributes used in each of the themes and the formula for calculating the total index were developed during a seminar with participants from government agencies, ministries, private sector as well as national and international NGOs. This joint development of the formula is crucial for the future use of the sensitivity index. The sensitivity index line has been reproduced on the environmental sensitivity maps (Fig. 3).

\section{Environmental sensitivity atlas}

The atlas covers the entire coastline and comprises three types of maps, each of which have been produced in 16 map sheets at scale 1:50 000 (Fig 1; Tychsen 2006).

\section{References}

Baker, J.M., Spalding, M.D., Moore, J. \& Tortell, P. 1994:. Sensitivity mapping for oil spill response. IMO/IPIECA Report Series 1, 24 pp.

Gundlach, E.R. \& Hayes, M.O. 1978: Vulnerability of coastal environments to oil spill impacts. Marine Technology Society Journal 12, $18-27$.

Tychsen, J. 2006 (ed.): KenSea - environmental sensitivity atlas for coastal area of Kenya, 76 pp. Copenhagen: Geological Survey of Denmark and Greenland.

UNEP 1998. Eastern Africa atlas of coastal resources, Kenya, 119 pp. Nairobi: UNEP.

\footnotetext{
Authors' address

J.T., Geological Survey of Denmark and Greenland, Øster Voldgade 10, DK-1350 Copenhagen K, Denmark. E-mail: jt@geus.dk

O.G.-H., AquaSim, Slagslunde Bygade 37, DK-3660 Stenløse, Denmark.

J.K., GeoQuest, Gyldenløvesgade 16, DK-1369 Copenhagen K, Denmark.
} 